\title{
Aminoterminal Propeptide of Type III Procollagen in Cord Blood and Amniotic Fluid of Appropriate-for-Gestational-Age Infants: A Predictor of Age-Related Fetal Growth Rate
}

\author{
PIET VANHAESEBROUCK, JOS KINT, MARC DHONT, CLAUDINE DE PRAETER, AND \\ JULES LEROY \\ Department of Pediatrics and Neonatal Medicine [P.V., J.K., C.D.P., J.L.], and Department of \\ Obstetrics and Gynecology [M.D.], University Hospital Gent, Gent, Belgium
}

\section{ABSTRACT}

Procollagen propeptide serum levels reflect the rate of collagen production. Because the prenatal period is unrivaled in terms of relative amounts of collagen synthesized per unit of time, this life episode must be the most sensitive period for the study of these biochemical markers of growth variability. N-terminal propeptide of type III procollagen (PIIINP) concentration was measured by two different methods (Fab'-fragment and whole antibodybased RIA assay) on paired samples of cord serum and amniotic fluid from a study cohort of 602 perinates with gestational age ranging from 20 to $41 \mathrm{wk}$. The aim of this study is to assess the clinical usefulness of the PIIINP assay for the evaluation of fetal somatic growth variation during the second half of normal pregnancies. It was demonstrated that the PIIINP level in cord serum, as well as in amniotic fluid, reflects age-related growth activity in "healthy" fetuses $(n=504)$ with normal intrauterine growth. This reflection was independent of the cumulative body mass or length

Because collagen is the main structural component of connective tissue, its generation must be a prerequisite for somatic growth (1). Earlier findings indicated a close relation between urinary excretion of hydroxyproline (a major amino acid constituent of collagen molecules) and growth rate throughout childhood (2).

Collagen type III, the most abundant protein in the extracellular matrix, is synthesized in the cell as procollagen III (1). After its secretion, the aminoterminal and carboxyterminal propeptides are cleaved off by specific peptidases and released into the serum (3). Their amount is in a stoichiometric relationship to the number of col-

Received March 18, 1993; accepted February 1, 1994.

Correspondence and reprint requests: P. J. Vanhaesebrouck, M.D., Department of Pediatrics and Neonatal Medicine, University Hospital Gent, De Pintelaan, 185, B-9000 Gent, Belgium.

Supported in part by Grant 3.0020.91 from the Medical Research Foundation of Belgium (F.G.W.O.). already attained at the time of investigation. The PIIINP concentration closely mirrors the shape of the fetal somatic growth velocity curve, expressed as weight-specific gain $(\mathrm{g} / \mathrm{kg} / \mathrm{d})$ during the second half of pregnancy. It can be concluded that PIIINP level in cord blood or amniotic fluid of fetuses with normal intrauterine growth is an interesting parameter for the assessment of maturity-related fetal growth potential. (Pediatr Res 36: 64-70, 1994)
PIIINP, N-terminal propeptide of type III procollagen OFC, occipitofrontal circumference
ABB, antibody-based RIA for PIIINP recognizing predominantly the intact propeptide (Col 1-3)
FAB, RIA for PIIINP using Fab' antibody fragments that are equally reactive with $\mathrm{Col} 1-3$ and $\mathrm{Col} 1$ fragments AGA, appropriate for gestational age $\mathbf{r}_{\mathbf{s}}$, Spearman rank correlation coefficient

lagen molecules formed and therefore reflects the rate of collagen synthesis.

During childhood, the serum concentration of PIIINP is tightly correlated with growth velocity. It closely mirrors the shape of the separate growth velocity curves in boys and girls (4-10).

The most rapid rate of somatic growth in humans occurs during fetal life. This episode is unrivaled in terms of relative amounts of collagen synthesized per unit of time (11). Physiologic growth, in the early fetus as well as in the postnatal human governed ultimately by his or her genetic constitution, is temporarily interfered with during late gestation by the limits imposed by uteroplacental anatomy and function (12). At that time, hormones are assigned a rather more restricted role of mediating the effects of substrate availability $(13,14)$. Because of these factors, there is a considerable variation in growth rate in the late gestation fetus in comparison with the growth 
rate in the first-trimester organism. Therefore, the late prenatal period is the most sensitive period for the study of biochemical indicators of growth variability.

The aim of the present study is to assess the clinical usefulness of the PIIINP assay in cord serum and in amniotic fluid for the objective evaluation of fetal growth variation during the second half of normally evolving pregnancies.

\section{METHODS}

Subjects. PIIINP concentrations were measured in cord serum, amniotic fluid, or both in a cohort of 602 newborn infants. The following perinatal data were registered on a computer database file before sample analysis: gravidity and parity, maternal age, maternal weight and weight gain, maternal length, maternal illnesses and pregnancy complications, placental weight, induction of labor, mode of delivery, infant's presentation, acid-base balance data in cord blood, Apgar scores, infant sex, plurality, birth rank, birth weight, length and OFC, major congenital anomalies, neonatal diseases, and in-hospital mortality. Gestational age was calculated as completed weeks after the mother's last menstrual period. Considered adequate for registration and further analysis were only those files in which the mother's dates were fully ascertainable or ultrasound confirmation of pregnancy before the 20th wk was available. Gestational age ranged from 20 to $41 \mathrm{wk}$ (mean $\pm \mathrm{SD}, 35.5 \pm 4.2 \mathrm{wk}$ ) and birth weight from 244 to $4700 \mathrm{~g}(2536 \pm 945 \mathrm{~g})$. Thirty-eight percent of the infants were born from primigravida and $42 \%$ from primiparous women. Seventy-six percent of the children were born vaginally and the remaining 143 by cesarean section. There were 329 boys and $273(45 \%)$ girls. One hundred thirty-six neonates belonged to multiple births (98 offspring in twin pregnancies, 31 in 11 triplets, and seven in two sets of quadruplets). Among the 602 newborns, 98 were classified as small-for-gestationalage infants because their birth weight was below the 10th percentile (matched for sex and parity) according to the Dutch data on intrauterine growth (15). These growthretarded infants were not further considered in the present part of our studies on PIIINP in newborn infants. In the group of AGA infants $(n=504), 45.6 \%$ were born after a pregnancy of less than 37 completed weeks. Thirty-seven neonates $(6.1 \%)$ died during the hospital stay, 31 among them during the first week of life. Forty-six infants had major congenital anomalies.

This study was carried out in the Children's Hospital, University of Gent, and it was approved by the ethical committee. Informed consent was obtained from the parents before they participated in the study.

Samples. Blood was collected from the cord or obtained within $12 \mathrm{~h}$ after birth by venipuncture or umbilical artery catheter. Serum samples were stored at $-20^{\circ} \mathrm{C}$ until assay. Amniotic fluid was collected by transmembranous aspiration during cesarean section or by transcervical aspiration through unruptured membranes during vaginal delivery. Meconium-stained or blood-containing amniotic fluid as well as those specimens originating from pregnancies complicated by premature rupture of membranes or chorioamnionitis were excluded. All samples were collected at the time of birth. No sample of amniotic fluid was obtained by a diagnostic amniocentesis procedure. After immediate centrifugation (2000 rpm, $10 \mathrm{~min})$, the clear supernatant was stored at $-20^{\circ} \mathrm{C}$ until the time of assay.

Biochemical methods. PIIINP concentration was measured in duplicate by a research version of the PIIINP assay (16). Monovalent Fab' antibody fragments are used instead of the antiserum (Behringwerke AG, Marburg, Germany). The intact aminoterminal propeptide (Col 1-3) and the monomeric Col 1 fragment are equally reactive with the antibodies. The intra- and interassay coefficients of variation for the FAB assay were 4.0 and $6.2 \%$, respectively.

PIIINP concentration was also measured by a commercially available antibody-based RIA (RIAgnost P-III-P, Behringwerke AG) that recognizes predominantly the intact propeptide (Col 1-3). This regular ABB assay using complete antibodies has only a weak affinity $(1 / 10)$ for the Col 1 fragments (17). The concentrations of serial dilutions (in duplicate) were determined using the $50 \%$ intercept method. The intraassay variation for the ABB assay on cord serum and amniotic fluid was 4.1 and $3.8 \%$, respectively. The corresponding interassay variation coefficients were 6.3 and $5.8 \%$.

Six hundred two cord serum samples were assayed by the FAB assay, and 114 of them were reassayed by the regular ABB test. Three hundred three amniotic fluid specimens were assayed by the ABB assay, and 96 were reassayed by the research $F A B$ test.

Statistical methods. Correlations between PIIINP levels and auxanologic data were evaluated by Spearman rank correlation analysis (18). A multivariate regression analysis was used to define those variables exerting influence independent of others. This procedure also allowed the calculation of the relative importance of the individual variables for predicting the PIIINP concentration in serum or amniotic fluid from the newborns in this study. The Mann-Whitney $U$ test was used for comparing prognostic groups. The results were considered significant when the $p$ value was less than 0.05 .

\section{RESULTS}

\section{Cord Serum PIIINP Levels of AGA Infants}

$F A B$ assay $(n=504)$. Linear regression analysis showed a highly significant negative correlation $(p<$ $0.0001)$ of the PIIINP serum level with gestational age ( $r_{s}$ $=-0.95)$ and birth weight $\left(r_{\mathrm{s}}=-0.81\right)$. Similar results were obtained for birth length, OFC, placental weight, and ponderal index (Table 1).

Ninety-two percent of the PIIINP serum level variability in AGA infants may be explained by only two of the variables, gestational age and OFC, as shown by step- 
Table 1. Correlation of cord serum PIIINP level (FAB assay) and amniotic fluid PIIINP level ( $A B B$ assay) with various independent auxanologic variables $(x): y=a+b x$

\begin{tabular}{lcc}
\hline & \multicolumn{2}{r}{$\mathrm{r}_{\mathrm{s}}$ for PIIINP in AGA infants* } \\
\cline { 2 - 3 } Independent variable $(\mathbf{x})$ & $\begin{array}{c}\text { Cord serum } \\
(n=504)\end{array}$ & $\begin{array}{c}\text { Amniotic fluid } \\
(n=268)\end{array}$ \\
\hline Gestational age $(\mathbf{w k})$ & -0.95 & -0.76 \\
Birth length $(\mathrm{cm})$ & -0.82 & -0.68 \\
Birth weight $(\mathrm{g})$ & -0.81 & -0.66 \\
OFC $(\mathrm{cm})$ & -0.75 & -0.61 \\
Placental weight $(\mathrm{g})$ & -0.49 & -0.38 \\
Ponderal index & -0.38 & -0.33 \\
\hline
\end{tabular}

${ }^{*} p<0.0001$ in all instances.

wise multiple regression analysis (forward and backward) for $\log$ PIIINP with six variables in the model: gestational age, birth weight, birth length, OFC, ponderal index, and birth weight to gestational age ratio [ $\log$ PIIINP = $(-0.126 \cdot$ gestational age $)+(0.03 \cdot$ OFC $)]$. When PIIINP levels were plotted separately for groups of extremely preterm, preterm, and term infants, the resulting correlation coefficients $\left(r_{s}\right)$ with corresponding birth weights were no longer significant, large variations in body weight notwithstanding (Table 2).

Maternal stature $(p=0.53)$ and body weight at the start of pregnancy $(p=0.87)$ did not show any correlation with the serum PIIINP level in the full-term AGA offspring $(n=262)$. Neither was there any correlation with maternal weight gain in pregnancies proceeding to term $\left(n=274: \mathrm{r}_{\mathrm{s}}=0.06, p=0.25\right)$.

The PIIINP level of 109 multiple-birth infants was not significantly $(p=0.1)$ different from that in single-birth infants matched for fetal lifetime. Moreover, neither birth order $(p=0.33)$ nor zygosity (12 complete monozygotic and 22 dizygotic twin pairs) $(p=0.82)$ made any difference in the corresponding PIIINP levels.

Tocolytic therapy was administered in 114 pregnancies. The AGA offspring had no significantly different PIIINP serum levels in comparison with the concentrations of age-matched neonates not submitted to prenatal tocolytic drugs $(n=390)$.

Gravidity, parity $(p=0.96)$, mode of delivery (vaginal or cesarean section, $p=0.78)$, induction of labor $(p=$ 0.09 ), and infant's presentation (vertex or breech, $p=$ 0.73 ) were not associated or were insignificantly associated with an altered propeptide serum value.

Perinatal asphyxia, defined as an Apgar score less than 6 at $5 \mathrm{~min}$ or a pH in arterial cord blood below 7.2, did not

Table 2. Correlation of cord serum FAB assay PIIINP concentration $(y)$ with birth weight $(x)$ in age-matched groups of $A G A$ neonates

\begin{tabular}{ccccc}
\hline $\begin{array}{c}\text { Gestational } \\
\text { age (wk) }\end{array}$ & $\begin{array}{c}\text { Number } \\
\text { of infants }\end{array}$ & $\begin{array}{c}\text { Birth weight } \\
\text { range }(\mathrm{g})\end{array}$ & $\mathrm{r}_{\mathbf{s}}$ for PIIINP & $\boldsymbol{p}$ value* \\
\hline $38-41$ & 230 & $2700-4620$ & -0.04 & NS \\
$33-36$ & 104 & $1520-3720$ & -0.16 & NS \\
$29-32$ & 95 & $1120-2520$ & -0.09 & NS \\
\hline
\end{tabular}

* $p$ value $\geq 0.05$. influence the PIIINP level $(p=0.16)$. This was also true for AGA infants dying in the first $48 \mathrm{~h}$ postdelivery in comparison with surviving infants matched for fetal lifetime $(p=0.85)$.

The PIIINP serum concentration in male AGA neonates $(n=282)$ was significantly higher $(p<0.005)$ than that in female AGA infants $(n=222)$. Statistical difference between sexes was present $(p<0.05)$ also if only term infants were considered $(n=135$ males and 145 females). The difference of the mean PIIINP value corresponded well with the percent difference $(4 \%)$ in mean body weight of the male and female infants, although in both age-matched groups separately, covariance analysis of PIIINP with birth weight was still shown to be irrelevant $(p=0.27)$.

Relationship between FAB and ABB assay PIIINP levels. One hundred fourteen cord serum samples from our newborn registration file $(n=602)$ were reassayed by the regular ABB test. A highly significant correlation between FAB and ABB levels of PIIINP was found in cord $\operatorname{serum}\left(\mathrm{r}_{\mathrm{s}}=0.82, p<0.0001\right)$.

Linear regression analysis for the ABB level in cord serum with gestational age $(n=102)$ as an independent variable showed a highly significant negative correlation $\left(r_{s}=-0.93, p<0.0001\right)$ as strong as that found earlier for cord serum FAB levels in AGA neonates $\left(r_{\mathrm{s}}=-0.95, p\right.$ $<0.0001$ ) (Fig. 1).

Percentile chart for cord serum PIIINP levels. The large number of data collected and used in the study of multiple potentially influencing variables allows the proposal of a percentile chart of FAB assay PIIINP cord serum concentration in AGA infants with gestational age ranging from 25 to 41 wk (Fig. 2). Covariance analysis with gestational age for PIIINP level collected in cord blood $(n$ $=463$ ) and with blood specimens collected on day 1 during the first $12 \mathrm{~h}(n=139)$ did not show any difference, allowing the admixture of both series of values on the same graph.

\section{Amniotic Fluid PIIINP Levels of AGA Infants}

$A B B$ assay $(n=268)$. Linear regression analysis showed a highly significant $(p<0.0001)$ negative correlation of amniotic fluid PIIINP level with gestational age $\left(r_{s}=-0.76\right)$ and birth weight $\left(r_{s}=-0.66\right)$ but also with other anthropometric data studied (Table 1).

Multivariate regression analysis showed that mainly gestational age $(F$ ratio $=847.6)$, independent of the other variables, could account for the amniotic fluid PIIINP level variability $(p<0.0001)$.

The correlation coefficient of the amniotic fluid PIIINP level with birth weight was no longer significant when age-matched full-term AGA-infants $(n=159)$ were considered separately, irrespective of very large variations in body weight (or length) within the group. This result applied also to premature $(n=37)$ and extremely premature $(n=41)$ AGA infants (gestational age 33 to 36 and 29 to 32 weeks, respectively). 


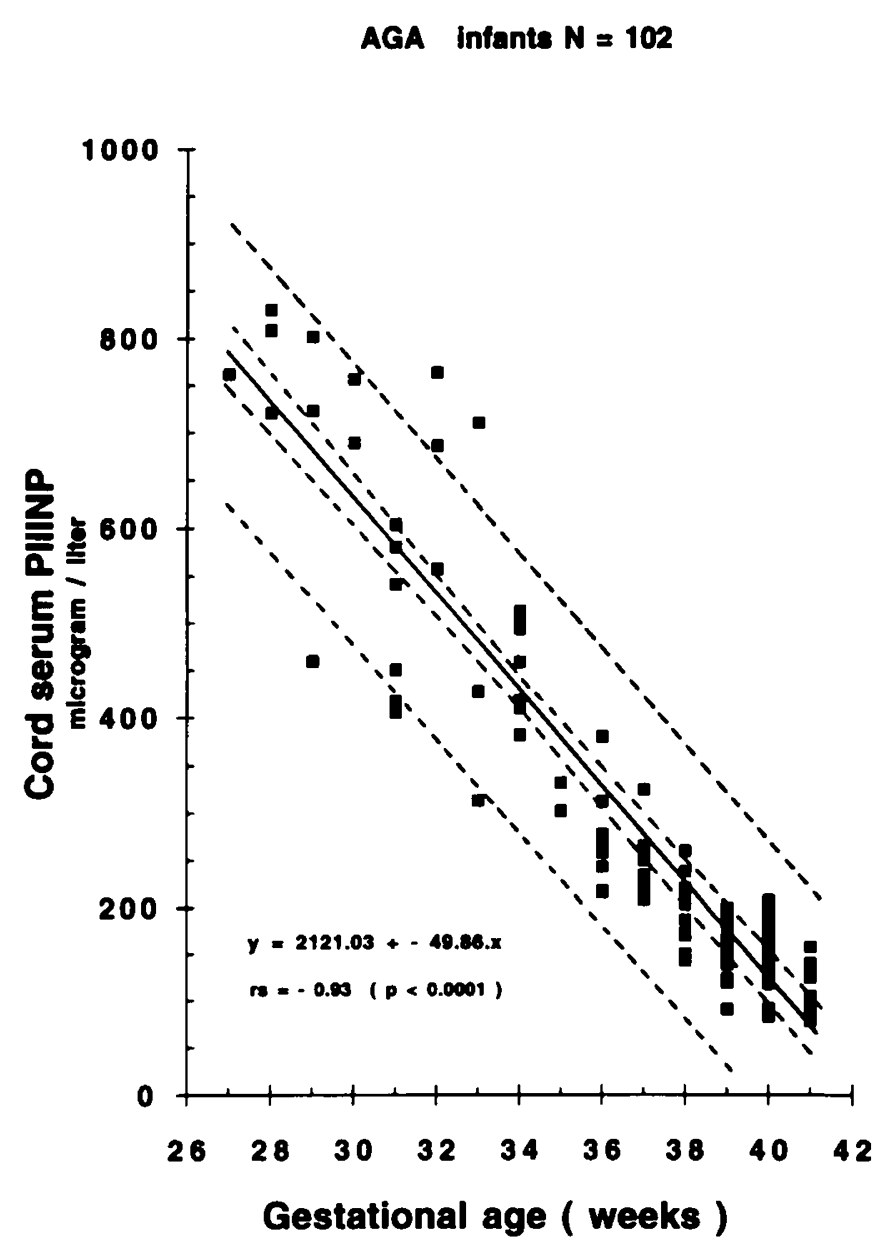

Figure 1. Correlation of cord serum ABB assay PIIINP level with gestational age as an independent variable $(x)$ recorded at weekly intervals in 102 AGA infants. The regression line and $95 \%$ confidence limits are shown for the mean and for individual values, respectively.

Sex, multiple birth, birth rank, and zygosity (for twins in diamniotic fluid compartments) did not influence the amniotic propeptide levels.

Propeptide concentration in amniotic fluid samples ( $n$ $=10$ ) collected during cesarean section of full-term AGA infants was not statistically different from the value of specimens $(n=159)$ collected transcervically during vaginal deliveries of age-matched AGA neonates $(p=0.47)$.

Relationship between $A B B$ and FAB assay PIIINP levels. Ninety amniotic fluid samples from our file $(n=303)$ were reassayed by the FAB assay. The FAB value ranged from 141 to $8020 \mu \mathrm{g} / \mathrm{L}$ (mean $2293.5 \mu \mathrm{g} / \mathrm{L}$ ) and the ABB level from 4.4 to $145 \mu \mathrm{g} / \mathrm{L}$ (mean $43.28 \mu \mathrm{g} / \mathrm{L}$ ), resulting in an average ratio of 50 to 1 . There was a very strong positive correlation between the two series of values $\left(\mathrm{r}_{\mathrm{s}}=0.94, p<0.0001\right)$ (Fig. 3).

Percentile chart for amniotic fluid PIIINP levels. A smoothed 10th- to 90th-percentile chart for ABB assay PIIINP values in amniotic fluid of AGA fetuses divided into 2-wk periods ranging from 27 to 42 wk was constructed (Fig. 4).

Crossover interrelationship between both assays in paired samples of cord serum and amniotic fluid. Paired samples

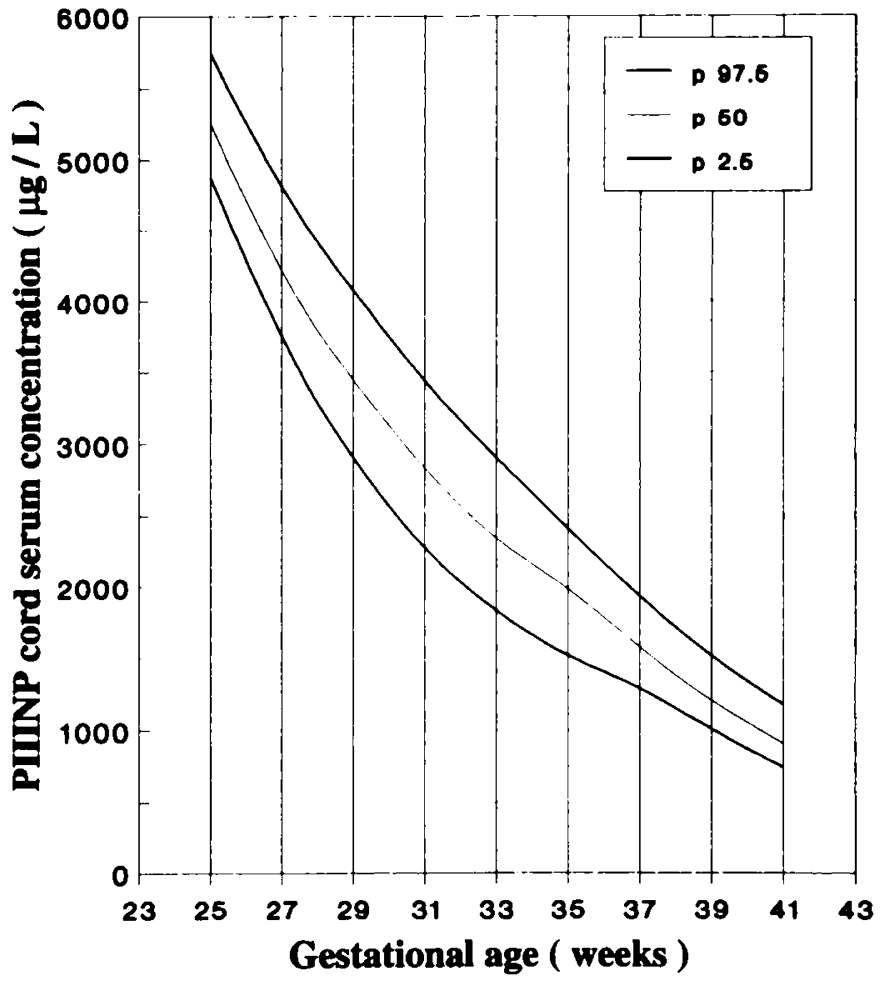

Figure 2. Percentile chart for cord serum FAB assay PIIINP levels in AGA infants (25-41 wk of gestation).

of cord serum and amniotic fluid from 96 newborn infants were both tested by the FAB assay and compared by linear regression analysis. A relatively weak, albeit significant, correlation was found $\left(r_{\mathrm{s}}=0.70, p<\right.$ 0.001 ).

Three hundred three cord serum specimens assayed by the FAB test could be equated to paired amniotic fluid samples probed for PIIINP by the ABB assay (Fig. 5). The ABB test values for PIIINP ranged from 4 to 145 $\mu \mathrm{g} / \mathrm{L}$ (mean $35.12 \pm 33.46 \mu \mathrm{g} / \mathrm{L}$ ). A significant positive correlation between the cord serum FAB assay PIIINP value and paired amniotic fluid ABB assay PIIINP level was found $\left(r_{\mathrm{s}}=0.76, p<0.0001\right)$.

\section{DISCUSSION}

At the outset of the study, it was presumed that in newborn infants in general, and even more so in prematurely born infants, it would be necessary to use a modified RIA for PIIINP to offer good quantitative accuracy. Our initial deliberate choice for the research FAB assay, which measures the intact propeptide as well as its degradation products, was supported by earlier biochemical studies. They showed that, using the unmodified antibodies, the inhibition curves of bovine or human purified Col 1-3 were not parallel to those obtained with serially diluted human sera or other human body fluids (such as amniotic fluid), precluding an adequate quantification of the propeptide $(17,19$, 20). This lack of parallelism indicated that not all the antigens in human fluids are totally identical with the 


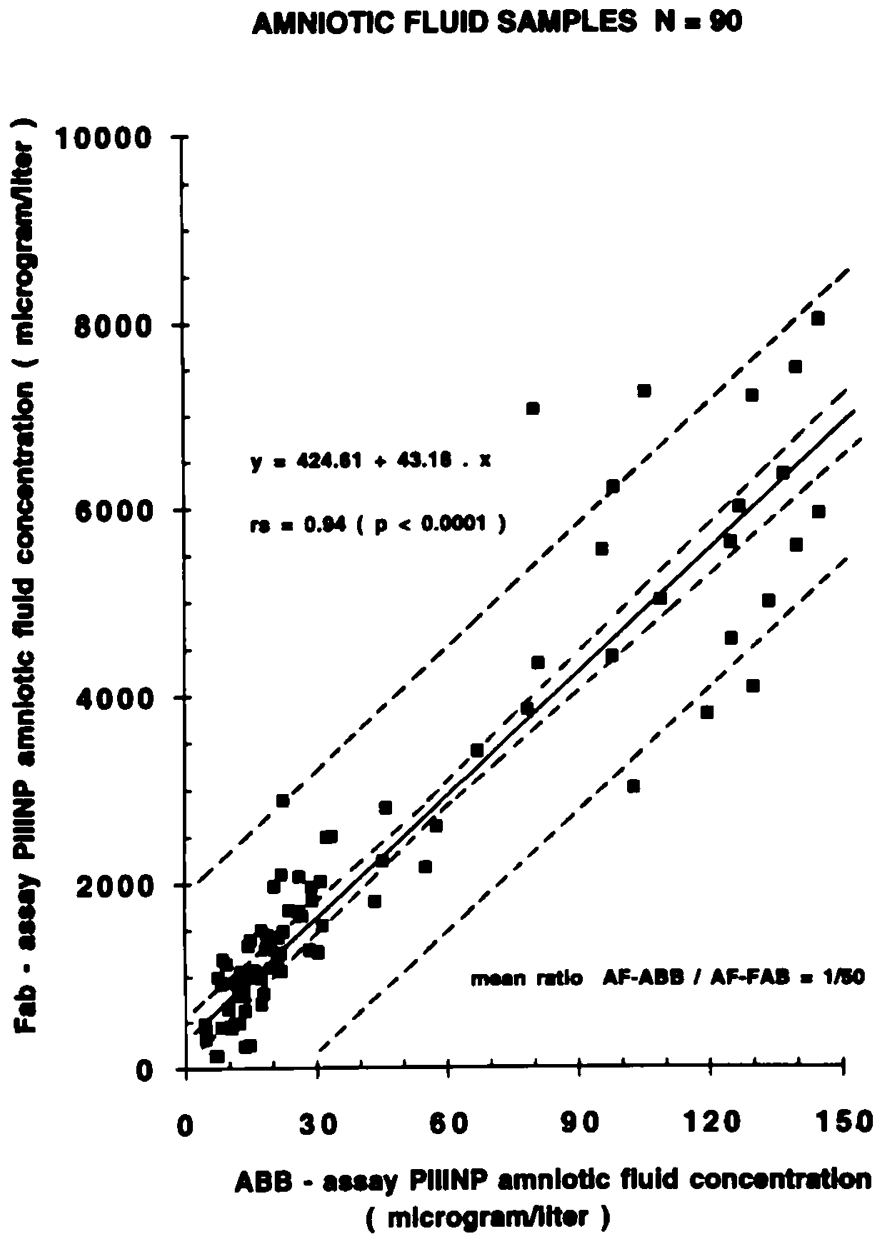

Figure 3. Correlation of ABB assay PIIINP level $(x)$ with FAB assay PIIINP level $(y)$ in 90 amniotic fluid samples. The regression line and 95\% confidence limits are shown for the mean and for individual values, respectively.

Col 1-3 peptide, as shown by gel filtration analysis of human serum (17). Therefore, assays that also measure the degraded forms $(e . g$. Col 1) were developed $(16,19)$. The average ratio between Col 1-3 propeptide concentration and the Col 1 fragment determined by molecular sieve chromatography is about $1: 4$ in the serum of adults. McCullogh et al. (21) showed that this ratio decreases with increasing PIIINP values (as seen in newborn infants). The regular PIIINP RIA using complete antibodies has only a weak affinity $(1 / 10)$ for the monomeric Col 1 fragments (17). Finally, from the data of Rhode et al. (16) and the study of Keller et al. (22), it was presumed that measurement of the PIIINP level in amniotic fluid by the conventional PIIINP RIA would be of low precision and sensitivity, because it was anticipated that mainly propeptide fragments would be present if originating from fetal urine (the major constituent of amniotic fluid in the late-gestation fetus), inasmuch as in adults proteolytic degradation apparently must precede the urinary excretion of the propeptide (16). However, recent data from Danne et al. (6) and Trivedi et al. (7) showed a very close relationship of the PIIINP level with childhood linear growth velocity

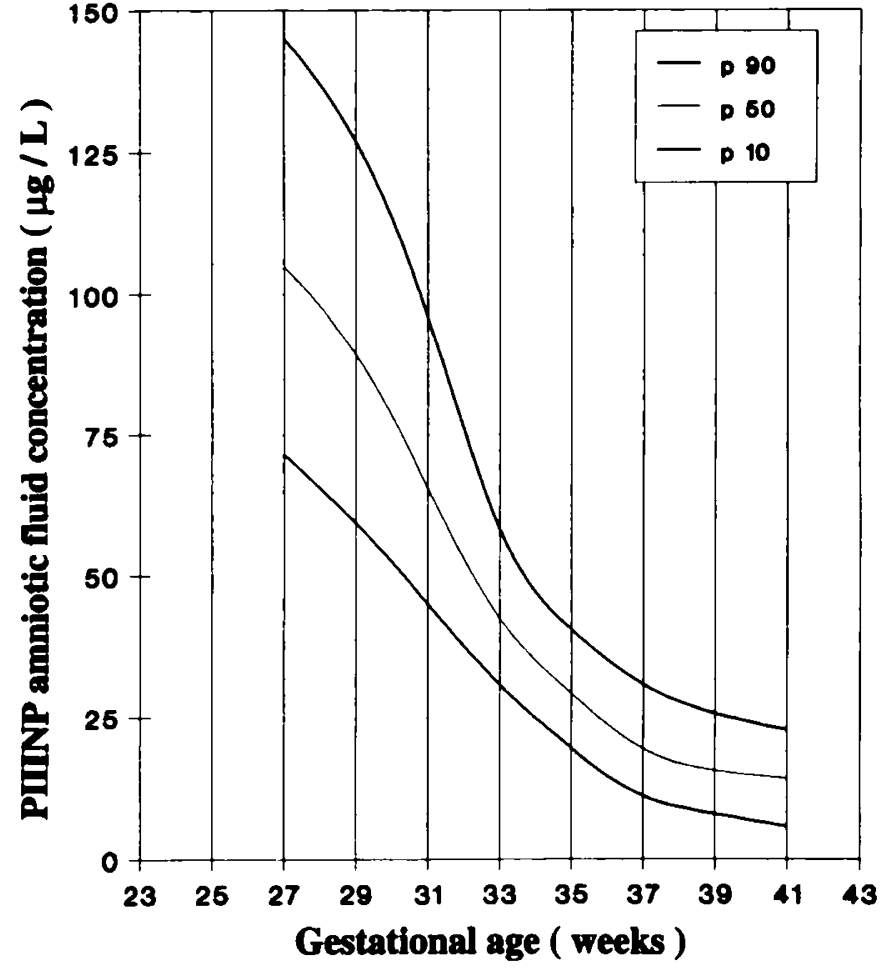

Figure 4. Percentile chart for amniotic fluid ABB assay PIIINP levels in AGA infants (27-42 wk of gestation).

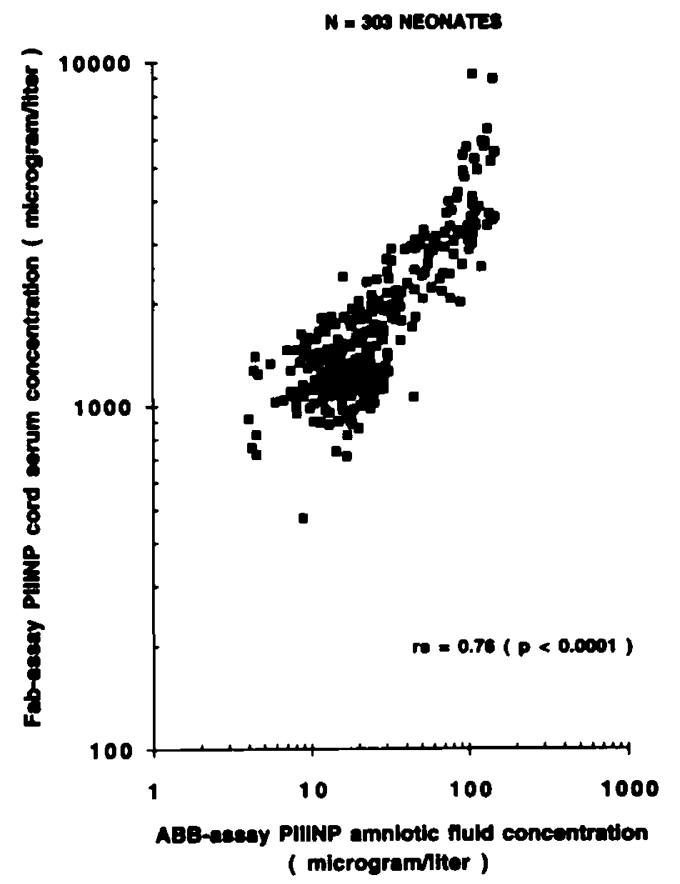

Figure 5. Correlation of cord serum FAB assay PIIINP level $(y)$ with paired amniotic fluid ABB assay PIIINP level $(x)$ in 303 newborn infants (logarithmic scales).

even in very young infants and also when measured by the regular whole-antibody PIIINP assay. They suggested that the standard assay would be even more sensitive in reflecting the growth process, because it is not dependent on its further catabolic fragmentation (4). Therefore, correlation studies involving both assay 
methods (FAB and $A B B$ ) in cord serum as well as in amniotic fluid were performed to assess their crossover interrelationship and interchangeability for clinical research on fetal growth activity.

The tightly interrelated $\mathrm{FAB}$ and $\mathrm{ABB}$ assay cord serum PIIINP levels both showed a highly significant negative correlation with gestational age in AGA infants. The on average seven times lower concentration of PIIINP measured by the ABB assay is in accordance with the data from other observers $(6,23)$. The strong positive correlation between ABB assay and FAB assay PIIINP levels in amniotic fluid and the mean ratio of 1:50 for the $A B B$ value compared with the $F A B$ level is consistent with the known lower affinity of the ABB assay for Col 1 fragments (17). It further supports the assumption that the propeptides in amniotic fluid mainly consist of their degraded forms, should their presence be dependent on fetal renal excretion. This remains to be proven, because we did not analyze the relative content of the different antigenic forms of PIIINP in our present study. From these crossover correlation studies, it may be concluded that, in spite of the theoretical objections mentioned earlier, both assays in the two biologic fluids, i.e. cord serum and amniotic fluid, apparently yield interchangeable results for the clinical evaluation of growth potential in the late gestation fetus. In the present study, it was further demonstrated that the PIIINP level in cord serum as well as in amniotic fluid reflects age-related growth activity in "healthy" AGA fetuses, independent of the cumulative body mass or length already attained at the time of investigation. No other biochemical test has been described with a similarly strong correlation to fetal lifetime. As has been demonstrated for subjects in later childhood in relation to linear growth velocity (4-10), the PIIINP level in cord serum and in amniotic fluid closely mirrors the shape of the fetal somatic growth velocity curve, expressed as weight-specific gain $(\mathrm{g} / \mathrm{kg} / \mathrm{d})(24)$ during the second half of pregnancy. In view of these results, it is important to appreciate that although the incremental weight gain ranges from $21 \mathrm{~g} / \mathrm{d}$ for the normal fetus growing alongside the 10th percentile to about 31 $\mathrm{g} / \mathrm{d}$ for the healthy 90th-percentile fetus, their growth velocity expressed as $\mathrm{g} / \mathrm{kg} / \mathrm{d}$ (weight-specific gain) is identical, slowing from $38 \mathrm{~g} / \mathrm{kg} / \mathrm{d}$ at $20 \mathrm{wk}$ to approximately 10 $\mathrm{g} / \mathrm{kg} / \mathrm{d}$ at term (25).

Most other perinatal variables studied were, predictably in most instances, of no influence on the serum propeptide level. These perinatal parameters could not be further evaluated in the smaller series of amniotic fluid assay results, but because cord serum and amniotic fluid propeptide levels are so closely related, even when measured by two different biochemical methods, it can be postulated that features of pregnancy and maternal organism relate to amniotic fluid PIIINP level as they did in cord serum. Interestingly, the well-known sex difference in infant body weight at birth is also reflected by congruent significant differences in PIIINP levels. Thus, it appears that not only the somatic growth rate but also the rate of collagen synthesis is probably monitored by the amount of serum testosterone available in fetal life (26).

It can be concluded that the PIIINP level in cord blood or amniotic fluid of fetuses with normal intrauterine growth is an interesting parameter for the assessment of maturity-related fetal growth potential.

Acknowledgments. The authors thank the nursing staff of the obstetrical and neonatal intensive care departments of the University Hospital and "Bijloke" Hospital Gent for their help in so efficiently organizing the collection of samples. The skillful technical support of Adil Huys and Odette Coessens is greatly appreciated. Adil Huys died prematurely during the last months that this work was carried out. This paper is dedicated to his commemoration. We also thank Georges Van Maele for invaluable advice and assistance with statistical data analysis.

\section{REFERENCES}

1. Prockop DJ, Kivirikko KI, Tuderman L, Guzman A 1979 The biosynthesis of collagen and its disorders. N Engl J Med 301(part I and II):13-23; 77-85

2. Wharton BA, Gough G, Williams A, Kitts S, Pennock CA 1972 Urinary total hydroxyproline: creatinine ratio. Range of normal and clinical application in British children. Arch Dis Child 47:74-79

3. Graham MF 1989 The use of serum levels of procollagen propeptides to predict growth velocity. J Pediatr Gastroenterol Nutr $8: 143-145$

4. Danne T, Gruters A, Schuppan D, Quantas N, Enders I, Weber B 1989 Relationship of procollagen type III propeptide-related antigens in serum to somatic growth in healthy children and patients with growth disorders. J Pediatr 114:257-260

5. Vainionpaa L, Risteli L, Lanning M, Myllyla V, Risteli J 1991 Aminoterminal propeptide of type III procollagen in cerebrospinal fluid. Variation with age and in childhood leukemia. Clin Chim Acta 203:47-56

6. Danne T, Gruters A, Schnabel K, Burger W, L'Allemand D, Enders I, Helge H, Weber B 1988 Long-term monitoring of treatment with recombinant human growth hormone by serial determinations of type III procollagenrelated antigens in serum. Pediatr Res 23:167-171

7. Trivedi P, Hindmarsh P, Risteli J, Risteli L, Mowat AP, Brook LG 1989 Growth velocity, growth hormone therapy, and serum concentrations of the amino-terminal propeptide of type III procollagen. J Pediatr 114:225230

8. Trivedi P, Cheeseman P, Portmann B, Hegarty J, Mowat AP 1985 Variation in serum type III procollagen peptide with age in healthy subjects and its comparative value in the assessment of disease activity in children and adults with chronic active hepatitis. Eur J Clin Invest 15:69-74

9. Hyams JS, Treem WR, Carey DE, Wyzga N, Eddy E, Goldberg BD, Moore RE 1991 Comparison of collagen propeptides as growth markers in children with inflammatory bowel disease. Gastroenterology 100:971-975

10. Jensen LT, Jorgensen JO, Risteli J, Christiansen JS, Lorenzen I 1991 Type I and III procollagen propeptides in growth hormone-deficient patients: effects of increasing doses of GH. Acta Endocrinol (Copenh) 124:278-282

11. Falkner F 1985 Perinatal growth. Arch Fr Pediatr 42:195-197

12. Gluckman PD 1989 Fetal growth: an endocrine perspective. Acta Paediatr Scand Suppl 349:21-25

13. D'Ercole AJ 1987 Somatomedins/insulin-like growth factors and fetal growth. J Dev Physiol 9:481-495

14. Rosenfeld RG, Wilson DM, Lee PD, Hintz HL 1986 Insulin-like growth factors $I$ and II in evaluation of growth retardation. J Pediatr 109:428-433

15. Kloosterman GJ 1969 Over intra-uteriene groei en de intrauteriene groeicurve. Maandschr Kindergeneesk 37:209-225

16. Rhode H, Langer I, Krieg T, Timpl R 1983 Serum and urine analysis of the aminoterminal procollagen peptide type III by radioimmunoassay with Fabfragments. Coll Relat Res 3:371-379

17. Niemela O, Risteli L, Sotaniemi EA, Risteli J 1982 Heterogeneity of the antigens related to the aminoterminal propeptide of type III procollagen in human serum. Clin Chim Acta 124:39-44

18. Glantz SA 1981 Primer of Biostatistics. McGraw-Hill, New York, pp 217-221

19. Pierard D, Nusgens BV, Lapiere CHM 1984 Radioimmunoassay for the amino-terminal sequences of type III procollagen in human body fluids measuring fragmented precursor sequences. Anal Biochem 141:127-136

20. Rhode H, Bruckner P, Timpl R 1983 Immunochemical properties of the aminopropeptide of procollagen type III. Eur J Biochem 135:197-202

21. McCullogh AJ, Strassen WN, Wiesner RH 1987 Serial determinations of the 
amino-terminal peptide of type III procollagen in severe chronic active hepatitis. J Lab Clin Med 109:55-61

22. Keller F, Rehbein C, Schwarz A, Fleck M, Hayasaka A, Schuppan D, Offermann G, Hahn EG 1988 Increased procollagen III production in patients with kidney disease. Nephron 50:332-337

23. Rohde H, Vargas L, Hahn E, Kalbfleisch H, Bruguera M, Timpl R 1979 Radioimmunoassay for type III procollagen peptide and its application to human liver disease. Eur J Clin Invest 9:451-459
24. Widdowsown EM 1974 Changes in body proportion and composition during growth. In: Davis JA, Dobbing J (eds) Scientific Foundations of Paediatrics. Philadelphia, WB Saunders, pp $44-45$

25. Dunn PM 1985 A perinatal growth chart for international reference. Acta Paediatr Scand Suppl 319:180-187

26. Rodeck CH, Gill D, Rosenberg DA, Collins WP 1985 Testosterone levels in midtrimester maternal and fetal plasma and amniotic fluid. Prenat Diagn 5:175-181 